\title{
Clinical outcomes after drug-eluting stent implantation for unprotected left main coronary artery disease
}

\author{
Francesco Pollice ${ }^{1}$, Paolo Pollice ${ }^{1}$, Lyan Jacob ${ }^{1}$
}

1) Department of Cardiology And Interventional Radiology. University Hospital Basel, Switzerland

\section{Summary}

Objective: Stenosis in the unprotected left main coronary artery (ULMCA) is considered a standard indication for surgical revascularization. Some studies have demonstrated that stenting of the ULMCA is safe and feasible in selected patients. Drug eluting stents (DES) have been shown to be superior to bare metal stents (BMS) in reducing restenosis and major adverse cardiac events (MACE) both in-hospital and at follow-up after treatment of ULMCA disease. Several studies showed that the mid-term prognosis of patients with left main stenting is good, but most of them are limited by small populations and the availability of mid-term results. Thus, we sought to evaluate the very long term impact of DES vs BMS in a large cohort of patients undergoing stent implantation for ULMCA disease in our center.

Material and Method: Between June 2002 and June 2008 a total of 354 consecutive patients with ULMCA stenosis were treated with percutaneous coronary intervention with BMS (53 patients) or DES (301 patients) implantation. A multivariable adjustment was provided in order to account for baseline differences between groups.

Results: The average clinical follow-up was $551 \pm 512$ days. Overall, MACE rate was significantly lower in the DES group ( $16.6 \%$ vs $26.4 \%$, $\mathrm{P}=0.02)$. The beneficial effect was driven by a reduction of death $(6.0 \%$ vs $9.4 \%, \mathrm{P}=0.11)$, MI $(2.7 \%$ vs $3.8 \%$, $\mathrm{P}=0.33)$ and target vessel revascularization after DES implantation $(9.0 \%$ vs $15.1 \%, \mathrm{P}=0.11)$. After correcting for independent predictors of adverse events, the adjusted hazard ratios (HRs) for the risk of mortality and myocardial infarction after DES implantation relative to BMS implantation were 0.99 ( $95 \%$ CIs 0.30-3.21, $\mathrm{P}=0.98)$ and 0.59 (95\% CIs $0.01-3.45, \mathrm{P}=0.56)$, respectively. The adjusted HR for two-year MACE was 0.50 (95 CIs 0.25 1.02), $\mathrm{P}=0.056$, mainly driven by a statistical significant reduction of TVR (HR 0.30 [95 CIs $0.11-0.82$ ], $\mathrm{P}=0.018$ ].

Conclusion: Patients presenting with ULMCA disease, who are treated with DES have a significant reduction in the rate of target lesion revascularization with no increased risk of death or myocardial infarction.

Keywords: Stroke, bare metal stents, drug eluting stents. 


\section{Introduction}

Among the inflammatory molecules, the role of Creactive protein (CRP) has been deeply investigated in the last few years and its importance as prognostic marker in patients with coronary artery disease is now quite clear, ${ }^{(2,3)}$ while less is known about inflammatory cytokines, which are also involved in the pathophysiology of atherosclerotic plaque. ${ }^{(4,5)}$ The authors studied macrophage colony stimulating factor (MCSF), a growing factor involved in the proliferation and differentiation of macrophages, inflammatory cells with a central role in plaque genesis and destabilization. 6-8 The aim of this study was to determine whether MCSF serum levels, measured during the acute phase, may be a useful marker to predict short term outcome in patients with ACS.

\section{Material and Method}

The authors studies 74 consecutive patients who were admitted to the Intensive Coronary Care Unit of the University of Palermo (Italy) for ACS, 48 men (65\%) and 26 woman (35\%), mean age 6612 years (range 46-87). According whit electrocardiographical (ECG) presentation, patients were distinguished as those with ST elevation myocardial infarction $($ STEMI,N. $=35)$ and those with non ST elevation myocardial infarction (NSTEMI, N.=39). The study protocol was conforming to the ethical guidelines of the Helsinki Declaration and all subjects gave their informed consent to participate to the study. At admission all subjects underwent a complete medical examination and the Killip's class was determined (according with the detection of clinical signs of left ventricle dysfunction). ${ }^{(9)}$ Moreover patients were asked about their past medical history and cardiovascular risk factors. Among the risk factors were: the presence of family history of cardiovascular disease (in a first- degree relative, younger than 55 years), hypertension (systolic or diastolic blood pressure respectively higher than $140 \mathrm{mmHg}$ or $90 \mathrm{mmHg}$ or the use of antihypertensive drugs), diabetes mellitus (fasting glucose plasma concentrations higher than $126 \mathrm{mg} / \mathrm{dL}$ or pharmacological therapy with oral hypoglycaemic drugs or insulin) smoking habits, obesity (body mass index $[\mathrm{BMI}]>30 \mathrm{~kg} / \mathrm{m}^{2}$ ) and dyslipidemia (triglycerides $>200 \mathrm{mg} / \mathrm{dL}$, total cholesterol $>200 \mathrm{mg} /$ $\mathrm{dL}, \mathrm{LDL}-\mathrm{C}>130 \mathrm{mg} / \mathrm{dL}$, HDL-C $<40 \mathrm{mg} / \mathrm{dL}$ in males and $<50 \mathrm{mg} / \mathrm{dL}$ in females). 10 Moreover, on admission a venous blood sample for the determination of MCSF, CRP and between MCSF and CRP concentrations were drawn. Among patients with STEMI 20 underwent primary percutaneous coronary intervention (PCI, 2 unsuccessful procedures), 7 were treated with thrombolysis ( 2 underwent rescue PCI) and 8 with medical therapy ( because previous treatments were not applicable). Patients with NSTEMI were initially treated with medical therapy and then, if not contraindicated, coronary angiography was performed. Among patients with patients with NSTEMI: 22 underwent PCI, 7 underwent $\mathrm{CABG}$ and in 10 other patients there was no indication for revascularization. During their hospital stay, patients underwent echocardiography (Siemens Sequoia machine) and ejection fraction (EF) was quantified by biplane Simpson method. ${ }^{(11)}$ Coronary angiography was performed in $84 \%$ of patients (angiographer Philips Integris 2000), according to ESC PCI guidelines. ${ }^{(12)}$ Coronary artery stenosis was considered to be significant if $50 \%$; subcritical if between $60 \%$ and $70 \%$ and critical if $70 \%$. The degree of coronary angiography (QCA). ${ }^{(13)}$ Patients were divided in 2 subgroups according to the severity of coronary artery: with one vessel disease and with multivessel disease. Clinical end points were short term outcomes in terms of cardiac death, recurrence of infarction or angina (pain similar in quality as the pain resulting in the presenting ACS, ECG changes). Two subgroup were identified according to the occurrence or not of adverse events during in- hospital stay.

\section{Assays}

Sera were obtained from blood within 30 minutes of venipuncture by clotting centrifugation at $4000 \mathrm{rpm}$ for $10 \mathrm{~min}$. Samples were aliquoted and frozen at -70 ${ }^{\circ} \mathrm{C}$ until assay. The laboratory measurements were performed by personnel unaware of the clinical data. Plasma MCSF concentrations were measured using a commercial enzyme- linked immunoassay (human MCSF, Quantikinine R\&D system, Minneapolis, MN).

The sensitivity of the assay is $20 \mathrm{pg} / \mathrm{mL}$. Total cholesterol, triglycerides and high density lipoprotein (HDL)- cholesterol were quantified by standard enzymatic- colorimetric methods, low density lipoprotein (LDL)- cholesterol was calculated by the Friedewald formula and fibrinogen with the Claus method. Fi- 
brinogen levels were considered to be normal between $200 \mathrm{mg} / \mathrm{dL}$ and $400 \mathrm{mg} / \mathrm{dL}$. The levels of CRP in the serum samples were determined by a high- sensitivity ELISA kit (IBL, Hamburg, Germany). I troponin was determined daily and peak value was considered (Luminescent immunometric reaction, Ortho- Clinical Diagnostic method).

\section{Statistical analysis}

Statistical analyses were performed using the Stat view Program (Abacus Concepts Inc.) Values were given as number and percentage or mean SD. T student's test was used to compare values of patients and controls; $\mathrm{x}^{2}$ test was used to compare STEMI and NSTEMI patients. The patients were divided in different subgroup stratified by the severity of coronary artery disease (2-3 vessel vs one vessel) and in hospital cardiac events (events vs no events): t student's test was used to patients. Differences were considered to be significant when obtained a $\mathrm{P}$ value $<0.05$. To correlate MCSF levels with CRP, the Sperman's rank correlation coefficient was used to compare these different subgroups of patients. Different subgroups of patients. Differences were considered to be significant when obtained a $\mathrm{P}$ value $<0.05$. To correlate MCSF levels whit CRP, the Spearman's rank correlation coefficient was used. A multiple regression analysis was performed to asses whether MCSF was a variable independently related with adverse events.

\section{Results}

Table I shows baseline characteristics of patients and differences among the subgroups with STEMI and NSTEMI. There was not a significant difference be-

\begin{tabular}{|c|c|c|c|}
\hline Table I & All patients $(\mathbf{N} .=35)$ & STEMI (N.=35) & NSTEMI (N.=39) \\
\hline Age (years) & 6612 & 64 & 68 \\
\hline \multirow[t]{2}{*}{ Sex (N. and \%) } & $48(65 \%)$ & $24(32 \%)$ & $24(32 \%)$ \\
\hline & $26(35 \%)$ & $8(11 \%)$ & $18(24 \%)$ \\
\hline Hypertension & $47(64 \%)$ & $25(71 \%)$ & $24(62 \%)$ \\
\hline Obesity & $19(26 \%)$ & $9(26 \%)$ & $10(26 \%)$ \\
\hline Diabetes mellitus & $23(31 \%)$ & $11(31 \%)$ & $12(31 \%)$ \\
\hline Current smokers & $28(39 \%)$ & $14(40 \%)$ & $14(36 \%)$ \\
\hline Family history of CAD & $38(51 \%)$ & $16(21 \%)$ & $22(56 \%)$ \\
\hline Dyslipidemia & $23(31 \%)$ & $10(46 \%)$ & $12(33 \%)$ \\
\hline Total chol (mg/dL) & 201.9495 .32 & 211.03133 .48 & 197.25102 .49 \\
\hline HDL chol (mg/dL) & 45.9415 .55 & 43.6114 .75 & 48.3616 .28 \\
\hline LDL chol (mg/dL) & 155.8555 .12 & 134.9146 .72 & 174.756 .33 \\
\hline Triglycerides (mg/dL) & 159.37148 .29 & 131.8553 .22 & 186.89201 .04 \\
\hline Troponin (ng/mL) & 24.9318 .99 & 31.0710 .93 & 17.76 .25 \\
\hline MCSF (pg/mL) & 332.9696 .00 & 326.65 & 297.15110 .43 \\
\hline Fibrinogen (mg/dL) & 424.52105 .6 & 472.07143 .87 & 390.0790 .77 \\
\hline CRP (mg/L) & 1.050 .45 & 1.23107 .55 & 1.010 .48 \\
\hline Killip's Class > II & $17(23 \%)$ & $6(17 \%)$ & $11(28 \%)$ \\
\hline EF (\%) & $5111 \%$ & $5311 \%$ & $4913 \%$ \\
\hline 2-3 vessels $C A D$ & $34(46 \%)$ & $15(43 \%)$ & $19(49 \%)$ \\
\hline
\end{tabular}


tween STEMI and NSTEMI patients in MCSF and CRP levels (respectively 326.65143 .87 vs $297.15110 .4 \mathrm{pg}$ / $\mathrm{mL}, \mathrm{P}=\mathrm{NS} ; 1.230 .48 \mathrm{mg} / \mathrm{L}, \mathrm{P}=\mathrm{NS})$. A correlation was found between CRP and MCSF levels $(\mathrm{P}=0.05$, Spearman rank $=0.30)$. MCSF levels were significantly higher in patients with single vessel disease compared with patients with two or three vessels disease (233.61 128.29 vs $330.03241 .51 \mathrm{pg} / \mathrm{mL}, \mathrm{P}=0.04$ ) as well as CRP ones ( 0.600 .22 vs $1.140 .50 \mathrm{mg} / \mathrm{L})$. As for the adverse events, among patients with STEMI: 5 died during in- hospital stay and 2 suffered from angina recurrence. Among NSTEMI patients, 4 deaths occurred, 3 recurrent anginas, and 1 re-infarction. Patients with in hospital fatal adverse events showed higher MCSF levels compared with those without adverse events (363.00 147.61 vs 251.00186 .69 pg/mL, $\mathrm{P}=0.03$ ). CRP levels were also raised in subjects with in hospital adverse cardiac events ("events" vs "no events" 1.040 .40 vs $0.970 .50 \mathrm{mg} / \mathrm{L}, \mathrm{P}=0.03$ ). Multiple regression analysis showed that MCSF was a variable independently associated with adverse events $(\mathrm{P}=0.0520)$.

\section{Discussion}

Less is known about the role of other inflammatory molecules. MCSF is a cytokine involved in the regulation of proliferation and differentiation of monocytes and macrophages and released by the injured endothelium. This plays an important role in destabilising the atheromatous plaque and in triggering ischemia. ${ }^{(7,8,15)}$
Previous studies already showed increased MCSF levels in patients with stable and unstable angina. ${ }^{(16,17)}$

Moreover, some authors observed how increased MCSF levels in patients with unstable angina may predict a worse prognosis during in hospital stay and in a mid to long term period. ${ }^{(16,18-21)}$ This study confirmed the importance of MCSF as a prognostic marker in acute coronary syndrome with its levels higher in patients with worse in hospital stay and more diseased coronary vessel. Moreover, for the first time the authors have observed the abserved the absence of significant statistical differences of its concentrations between STEMI and NSTEMI patients.

This underlines how MCSF levels reflect the inflammation burden and not the amount of necrosis. Moreover, MCSF is a marker of inflammation, this finding reinforce the hypothesis that inflammation is the common pathway of ACS, which mainly differs in the degree of thrombosis, that may be occlusive and persistent leading to STEMI or transient leading to NSTEMI and not in the pathophysiological background. ${ }^{(22)}$

\section{Conclusion}

This study supports the hypothesis that inflammation is involved in the pathophysiology of ACS and that MCSF plays a novel and intriguing role, in predicting the patient's prognosis. In order to confirm this fascinating hypothesis further and extensive studies are needed. 


\section{References}

1. Libby P. Current concepts of the pathogenesis of the acute coronary syndromes. Circulation 2001;104:365.

2. Biasucci LM,Liuzzo G, Grillon RT, Caliguri G, Rebuzzi AG, Buffon A et al. Elevated $\mathrm{C}$ reactive protein at discharge in patients with unstable angina predicts recurrent instabily. Circulation 1999;99:855-60.

3. Pearson TA, Mensah GA, Alexander RW, Anderson JL, Cannon RO 3rd, Criqui $\mathrm{M}$ et al. Markers of inflammation and cardiovascular disease: application to clinical and public health practice: a statement for healthcare professionals form the Centres for Disease Control and Prevention and the American Heart Association. Circulation 2003;107:499-511.

4. Novo S, Basili S, Tantillo R, Falco A, Davi V, Novo G et al. Soluble CD40L and cardiovascular risk in symptomatic low-gradecarotic stenosis. Stroke 2005;36:673-5.

5. Ferroni P, Novo S, Davi V, Novo G, Basili S, Davi G. Circulating transforming growth factor-beta 1 levels in asymptomatic carotid plaques. Stroke 2005;36:525-6.

6. Libby P, Ridker PM, Maseri A. Inflammation and atherosclerosis. Circulation 2002;05:1135-43.

7. Moreno RP, Falk E, Palacios IF, Newell JB, Fuster V, Fallon JT. Macrophage inflitration in acute coronary syndromes: implications in plaque rupture. Circulation 1994;90:775-8.

8. Roth P, Standley ER. The biology of CSF-1 and its receptor. Curr Top Microbiol Immunol 1992;181:141-67.

9. Scheidt S, Wilner G, Fillomore S, Shapiro M, Killip T. Objective haemodynamic assessment after acute myocardial infraction. Br Heart $J$ 1973;35:908-16.

10. Grundy SM, Cleeman JL, Bairey Merz CN, Brewer HB Jr, Clark LT, Hunninghake DB et al. Implications of recent clinical trials for the national cholesterol education program. Adult Treatment Panel III Guidelines. Circulation 2004;110:227-39.

11. Stamm RB, Carabello PA, Martin RP, Twodimentional echocardiographic measurement of left ventricular ejection fraction: prospective analysis of what constitutes an adeguate determination. Am Heart J 1982;104:136.

12. Silber S, Albertsson P, Aviles EF, Camici PG, Colombo A, Hamm C et al. Guidelines for percutaneous coronary intervention. The task Force for Percutaneous Coronary Interventions of the European Society of
Cardiology Eur Heart J 2005;26:804-47.

13. Stadius ML, Alderman EL. Coronary artery revascularization-critical need for and consequence of objective angiography assessment of lesion severity. Circulation 1990;82:2231.

14. Coppola G, Corrado E, Muratori I, Tantillo R, Vitale G, Lo Coco L et al. Increased levels of C-reactive protein and fibrinogen infuence the risk of vascular events in patients with NIDDM. Int J Cardiol 2006;106:16-20.

15. Lendon CL, Davies MJ, Born GV, Richardson PD, Aterosclerotic plaque caps are locally weakend when macrophage density is increased. Atherosclerosis 1991;87:87-90.

16. Ikonomidis I, Lekakis J, Revela I, Andreotti F, Nihoyannopoulos P. Increased circulating $\mathrm{C}$ reactive protein and macrophage colony stimulating factor are complamentary predictors of long term outcome in patients with chronic coronary artery disease. Eur Heart $J$ 2005;26:1618-24.

17. Hoyo Y, Ikeda U, Takahashi M, Shimada K. Increased levels of monocyte derived cytochine in patiets with unstable angina. Atherosclerosis 2002;161:403-8.

18. Rallidis LS, Zolindaki MG, Manioudaki HS, Laoutaris NP, Velissaridous AH, Papasterialds EG, Prognostic value of C-reactive protein, fibrionogen, interleukin 6 and macrophage colony stimulating factor in severe unstable angima. Clin Cardiol 2002;25:505-10.

19. Saitoh T, Kishida H, Tsukada Y, Fukuma Y, Sano J, Yastutaka M et al Clinical significance of increased concentration of macrophage colony stimulating factor in patients with angina pectoris. $\mathrm{J} \mathrm{Am} \mathrm{Coll} \mathrm{Cardiol}$ 200;35:655-65.

20. Naghavi M, Libby P, Falk E, Casscells SW, Litovsky S, Rumberger J et al. From vulnerable plaque to vulnerable patient: a call for new definitions and risk assessment strategies: Part I. Circulation 2003;8:564-70.

21. Postiglione L, Montagnani S, Ladogana P, Castaldo C, Di Spigna G, Bruno EM et al. Granulocyte Macrophage Colony Stimulating Factor receptor expression on human cardiomyocytes from end-stage heart failure patients. Eur J Heart Fail 2006;8:564-70.

22. Maekawa Y, Anzai T, Yoshikawa T, Sungo Y, Mahara K, Khono T et al. Effect of granuloicyte-macrophage colony stimulating factor inducer on left ventricular remodelling after acute myocardial infarction. $J$ Am Coll Cardiol 2004;44:15-20

Received: 16/08/2012

Accepted: 11/12/2012

Published: 23/02/2013

Disclosure and conflicts of interest:

Conflicts of interest were not reported.

Corresponding author:

Dr. Francesco Pollice

Mail: francesco.pollice@tiscali.it 